\title{
Relectura de la noción de industria cultural de Theodor Adorno*
}

\author{
Manuel Silva Rodríguez ${ }^{* *}$
}

Recibido: 2 de mayo de 2013 - Aprobado: 7 de junio de 2013

\begin{abstract}
Resumen
El texto presenta una revisión de la noción de industria cultural, propuesta por Theodor Adorno junto a Max Horkheimer en 1947 y desde entonces presente en el análisis y el debate cultural. El artículo expone los elementos que integran esta categoría y para tratar de entenderla en toda su dimensión la encuadra en el contexto general del pensamiento de Adorno. Además de señalar varias críticas que la noción ha recibido, el texto destaca algunos aspectos que poco han sido valorados por sus críticos y algunos de sus límites y posibles alcances.

Palabras clave: arte, dialéctica de la Ilustración, industria cultural, mass media, sistema, Theodor Adorno.
\end{abstract}

* Este artículo presenta resultados de la investigación La presencia del mal en el arte. Una mirada desde el pensamiento estético de G. Bataille y Th. Adorno. La investigación fue realizada en la Universidad de Antioquia, en el marco de la Maestría en Filosofía del Instituto de Filosofía, y contó con recursos institucionales y propios.

* Docente - investigador Universidad del Valle. Comunicador social y magíster en Filosofía (Universidad de Antioquia). Doctor en Teoría de la Literatura y Literatura Comparada (Universidad Autónoma de Barcelona). Profesor asociado Escuela de Comunicación Social-Universidad del Valle, Cali, Colombia. Correo: manuel. silva@correounivalle.edu.co. El texto tiene origen en la investigación realizada para optar al título de Doctor en Teoría de la Literatura y Literatura Comparada. Correo electrónico: manuel.silva@correounivalle. edu.co. 


\title{
Re-Reading of the Notion of Cultural Industry of Theodor Adorno
}

\begin{abstract}
The article shows a revision of the notion of Cultural Industry proposed by Theodor Adorno and Max Horkheimer in 1947; notion present ever since in cultural analysis and debate. The article exhibits the elements comprising this category and, as a way to entirely understand such a notion, the article places it within the general context of Adorno's thinking. In addition to establishing several reviews made to the notion, the article outlines some aspects not widely taken into consideration by critics and some of its limitations and possible scopes.
\end{abstract}

Key words: art; illustration dialectics; cultural industry; mass media; system; Theodor Adorno. 


\section{Introducción}

Este artículo propone un acercamiento a la noción de industria cultural (IC) en el pensamiento de Theodor Adorno. El texto procura establecer, si no todos, la mayoría de los elementos vinculados a la noción, tal como fue formulada por Adorno en compañía de Max Horkheimer en La industria cultural. La Ilustración como engaño de masas (1947), en el marco de la Dialéctica de la Ilustración, y como posteriormente la refrendó en el breve ensayo Resumen sobre la industria cultural (1963) y en múltiples fragmentos y pasajes de la Teoría estética (1970). A partir de la identificación de tales elementos y del contenido teórico que Adorno les asigna, sin perder de vista algunas ideas expuestas por él en otros lugares ${ }^{1}$-ideas pocas veces tenidas en cuenta por comentaristas y críticos- y el contexto histórico en el cual surge la noción de IC, el texto intenta presentar una mirada crítica tanto sobre los límites de su formulación como sobre lo que puede ser su actualidad. De esta manera, el artículo pretende mostrar la amplitud de una categoría que, aproximadamente desde mediados del siglo XX, ha estado presente en los debates sobre el arte, la cultura y la comunicación, hasta llegar, con un sentido fundamentalmente instrumental, a formar parte de las políticas económicas y culturales de gobiernos nacionales y locales, y del abanico de inversiones del capital privado².

\section{Metodología}

En el proceso de investigación se estableció, en primer lugar, identificar los principales textos en los cuales Adorno expuso su concepción de la IC. Esto supuso, además, reconocer el momento histórico en el cual el filósofo alemán elaboró y dio consistencia teórica a su pensamiento. En este sentido, como se indicó más arriba, fueron tomados como fundamentales los ensayos La industria cultural. La Ilustración como engaño de masas (1947), Resumen sobre la industria cultural (1963) y la Teoría estética (1970). En segundo lugar, la investigación implicó acercarse a otros textos de Adorno menos conocidos y citados, en

1 Aunque no voy a detallar la relación entre los dos textos, merece la pena señalar que en un escrito de 1938 se encuentran muchas ideas sobre la industria cultural expuestas por Adorno en el ensayo redactado junto a Horkheimer y en otros posteriores. En efecto, si bien Adorno no introduce allí la noción de IC ya en ese escrito, en el que critica duramente el jazz, se hallan categorías como la de la pérdida de la autonomía del arte, la de un arte de entretenimiento como un arte falso y la del receptor de este arte como un público alienado. En ese texto, por ejemplo, dice: "Todo arte «fácil» y agradable se ha vuelto arte aparente y falaz"; "la totalidad de la vida musical del presente está dominada por la forma de la mercancía"; "Es más bien el escuchar contemporáneo el que ha retrocedido, el que se ha fijado a una escala infantil" (2009a, pp. 19, 25 , 34).

2 Como muestra del interés del sector gubernamental en lo perfilado por los frankfurtianos está el tomo publicado por la Unesco en 1982 (Industrias culturales: El futuro de la cultura en juego. México: FCE-Unesco), fruto de una convocatoria hecha con el fin de identificar elementos para trazar políticas multiestatales. Otra muestra más reciente la constituyen los apartados de industrias culturales que aparecen en páginas web oficiales como la del Ministerio de Cultura de Colombia y de la Alcaldía de Santiago de Cali, por citar dos casos del orden nacional. Por último, en lo que testimonia el perfeccionamiento y la proliferación en tiempos actuales de los procedimientos de producción planificada y en serie de bienes simbólicos esbozada por Adorno en los años 40, está el libro Cultura mainstream. Cómo nacen los fenómenos de masas (2011), de Frédéric Martel. 
los cuales se puede apreciar que con el paso del tiempo el autor matizó algunas ideas de 1947. De esta manera, el trabajo buscó comprender en su complejidad una noción cuyo sentido no se puede aislar de la amplitud del pensamiento de Adorno. Con esta misma finalidad, la investigación consideró la lectura de las interpretaciones que una serie de autores, situados en diversas disciplinas, han hecho de la IC. Con ello se procuró tanto contrastar como actualizar la comprensión y la vigencia de esta categoría. De esto último se da cuenta en las conclusiones.

\section{Elementos de la noción de industria cultural}

Como se sabe, las definiciones son bastante extrañas en la producción filosófica de Adorno. Su método paratáctico y la configuración de constelaciones para poner en conceptos aquello que en cada caso hacía mover su pensamiento hacen que algunas de las categorías centrales de su filosofía no las hallemos establecidas de una vez y con un sentido estático. Por el contrario, lo corriente es encontrarlas dotadas de cierta movilidad y revestidas de un carácter que puede surgir, de un modo y con un alcance particulares, en un ámbito, y luego reaparecer con otros, afines pero no exactamente iguales, en un lugar diferente. Así sucede, por ejemplo, con las categorías de la no-identidad y la negatividad, las cuales podemos hallar con valores próximos y a la vez singulares en dominios como la teoría sobre la sociedad y la cultura, la estética o la epistemología.

A este rasgo del pensamiento de Adorno no se sustrae la noción de IC. No obstante, como punto de partida propongo una breve definición de lo que en el ensayo publicado en 1947 podemos entender por industria cultural. En ese texto la IC refiere el sistema de producción industrial de artefactos estéticos idénticos en su estructura y en su sentido, hechos en y para ser circulados en los medios masivos de comunicación y para ser dirigidos al consumo masivo de un público construido por la propia industria ${ }^{3}$. Creo que esta síntesis de la noción de IC de Adorno -sin detallar aún la racionalidad, la finalidad y los efectos que él le atribuye- tiene correspondencia con un pasaje que, nada más al empezar La industria cultural, leemos: "Cine, radio y revistas constituyen un sistema. Cada sector está armonizado en sí mismo y todos entre ellos" (Horkheimer, Adorno, 1998, p. 165); y cuando más adelante hallamos: "La constitución del público, que en teoría y de hecho favorece al sistema de la industria cultural, es una parte del sistema, no su disculpa" (p. 167).

Como se puede ver, en las ideas de Adorno encontramos implicado un conjunto de elementos que son los que en su relación dotan de complejidad la noción de IC. Esta misma postura la mantiene en el posterior Resumen sobre la industria cultural:

3 La noción de Adorno también ha sido interpretada así: "Industria cultural. La ineludible apropiación. Ideología totalitaria que todo lo atrapa y mercantiliza, haciendo que se diluya en el puro orden del consumo. La producción en serie de la cultura, de eso se trata; no la cultura de masas y sus connotaciones, podríamos decir, de carácter populista, sino, más propiamente, la construcción de todo un entramado de producción cultural y artística que masifica al objeto estético «lanzándolo» sobre las leyes del mercado y probando una oferta sin ser todavía demanda" (Dipaola, Yabkowski, 2008, p. 33). Y en otro lugar ha sido descrita de esta manera: "El término «Kulturindustrie», creado por Adorno, designa la explotación sistemática y programada de los «bienes culturales» con fines comerciales" (Jimenez, 2001, p. 72). 
En todos sus sectores [la industria cultural] fabrica de una manera más o menos planificada unos productos que están pensados para ser consumidos por las masas y que en buena medida determinan este consumo. Los diversos sectores tienen la misma estructura, o al menos encajan unos con otros. Conforman un sistema que no tiene hiatos. Esto sucede gracias a los medios actuales de la técnica y a la concentración de la economía y la administración (2008, p. 295).

La noción de IC, pues, aparece integrada por lo que en Adorno abarcan las categorías de sistema, esquematismo, dominio, ideología, medios, público o consumidores, producción en serie de mercancías culturales, técnica, tiempo libre, y la dicotomía arte serio-arte ligero. Veamos entonces cómo se relacionan estos elementos para conformar un sistema.

Como se dijo más atrás, el marco filosófico en el cual Adorno formula la noción de IC es el de la Dialéctica de la Ilustración. Recordemos que en el primero de los ensayos que componen esa obra, Concepto de Ilustración, Adorno y Horkheimer consignan las ideas que orientarán su crítica a la razón instrumental. Es allí donde los autores afirman que en cuanto la razón ha pretendido ordenarlo todo ha operado como el mito, lo cual, por lo tanto, explica: que la Ilustración haya recaído en el mito y en la barbarie; que al comportase así, la razón se haya mostrado fundamentalmente como instrumento de dominio de los hombres sobre los hombres y sobre la naturaleza; y que la técnica, como expresión del pensamiento que calcula y busca la utilidad, haya sido el modo de desarrollo de esta racionalidad. En este ensayo, por ejemplo, leemos: "La técnica es la esencia de tal saber. Este no aspira a conceptos e imágenes, tampoco a la felicidad del conocimiento, sino al método, a la explotación del trabajo de los otros, al capital" (1998, p. 60); "La Ilustración reconoce en principio como ser y acontecer solo aquello que puede reducirse a la unidad; su ideal es el sistema, del cual derivan todas y cada una de las cosas" (p. 62); "La sociedad burguesa se halla dominada por lo equivalente. Ella hace comparable lo heterogéneo reduciéndolo a grandezas abstractas" (p. 63).

Asimismo, es necesario recordar unos datos mínimos del contexto social e histórico en el cual Adorno elabora su concepto de IC. Recordemos que la juventud de Adorno transcurrió durante las primeras décadas del siglo XX, un período en el cual se formaron las principales vanguardias artísticas europeas, Alemania protagonizó la I Guerra Mundial y tras su derrota dio lugar a la frustrada y frustrante República de Weimar y al cultivo del espíritu del nacionalsocialismo que daría vida al Tercer Reich. Poco después de que los nazis asumieron el control total, Adorno, junto a Horkheimer, dejó Alemania y tras un corto paso por Inglaterra se trasladó a Estados Unidos, primero a Nueva York y después a California. Su experiencia en ambos mundos, uno determinado por el nazismo y otro por la emergencia de lo que más tarde se llamaría sociedad de consumo, fue decisiva en su pensamiento para denunciar cómo en la Modernidad los poderes político y económico determinaban toda la esfera social, incluidos el arte y la vida cotidiana e íntima.

En este trasfondo, entonces, para Adorno la producción industrial de mercancías se yergue como una concreción de la razón instrumental que interviene en distintos ámbitos de la sociedad, entre ellos el del arte y la cultura. Aquí advertimos que las ideas con las cuales Adorno suscribe junto a Horkheimer la caracterización y la crítica de la razón que 
sirve al dominio están presentes en la concepción de la IC. Como la razón instrumental, la IC opera de forma sistemática. Esta es una de las ideas nucleares de Adorno, de acuerdo con la cual en la IC existe una coordinación entre los distintos agentes que poseen el poder político y económico, los diferentes sectores en los que se divide la producción mediática y los diversos estamentos que integran cada medio de comunicación. Dicho en otros términos, de esta manera Adorno advierte que la IC es un sector más entre los que componen el orden articulado del mundo moderno de los negocios y de la política. La IC, perfilada así, es un instrumento de los intereses del poder.

Caracterizar la IC como sistema implica considerar la articulación de los demás elementos que integran la noción. Entender, a su vez, el sistema como una unidad de la cual derivan todos y cada uno de sus componentes exige pensar en el tipo de poder bajo el cual se articula el sistema, es decir, los intereses de dominio a los cuales sirve la razón instrumental. Para Adorno, quedó dicho, estos poderes son el político y el económico. Ya sea el poder totalitario de los regímenes fascistas o comunistas o la expansión desenfrenada del poder económico en las democracias liberales, en ambos casos la IC es un subsistema que forma parte del sistema mayor: aquel que consiste en la organización social determinada por la racionalidad del dominio. Este es un punto crucial de la reflexión de Adorno, de acuerdo con el cual la IC ya sea como propaganda -y no solo en sistemas fascistas- o como entretenimiento sirve a la conservación y a la reproducción de un orden social, político e ideológico.

Ahora bien, la caracterización de la IC como una unidad de la cual derivan todas sus partes también nos lleva a considerarla como un orden que admite solo lo que se ajusta a sus intereses e intenciones y que excluye o absorbe todo lo demás. En este lugar se nota la relevancia de la relación sistema-poder. Desde este punto de vista, bajo la IC solo serán admisibles las ideas y los productos que se acoplen a los intereses y las intenciones del poder. Lo opuesto o extraño al poder será invisibilizado, eliminado o integrado: "Lo que se resiste puede sobrevivir solo en la medida en que se integra. Una vez registrado en sus diferencias por la industria cultural, forma ya parte de esta como el reformador agrario del capitalismo. La rebelión que tiene en cuenta la realidad se convierte en la etiqueta de quien tiene una nueva idea que aportar a la industria" (1998, p. 176). Esta visión de la IC la representa como un pulpo cuyos tentáculos se extienden por doquier y sujetan a su voluntad la producción cultural, la cual en esta visión de Adorno se circunscribe básicamente a los productos de los mass media. En ese juego por el control, lo desconocido y la novedad, aquello que en un momento dado rompa con la uniformidad, terminará por tener un lugar previsto en la IC gracias al cálculo que rige la organización del sistema. En tal sentido la novedad, tan cara al arte moderno, será una de las necesidades que la IC buscará acomodar a sus intereses e incentivar y satisfacer en el público.

La producción de artefactos culturales que satisfagan las premisas del poder, ya sea en la forma de lo previamente aceptado o de la integración de lo extraño o novedoso, encontrará en la técnica el medio adecuado para concretar sus intereses en productos concretos. Aquí hay que precisar que en el lenguaje del ensayo La industria cultural a veces 
es difícil distinguir entre técnica y tecnología, pues Adorno utiliza ambas categorías para referir rasgos de la IC. Ya sea la técnica como un saber hacer administrado y codificado o la tecnología como un desarrollo material para aplicar en la praxis social un saber hacer, para él la técnica y la tecnología sirven de soporte a la realización de los intereses del poder a través de la creación de un modelo de producción industrial. No es que Adorno no reconociera lo particular de una y otra categoría, su juicio es que en la IC la tecnificación administrativa con su respaldo en la instrumentación tecnológica determina la técnica creativa ${ }^{4}$. Constituido como estilo industrial, el saber hacer acorde con los planes de la IC se sitúa así como el momento racional fundamental en el orden establecido por el sistema. Esta racionalidad será el instrumento adecuado para que el sistema se articule en su unidad y coherencia. Por eso dirá Adorno: "La racionalidad técnica es hoy la racionalidad del dominio mismo" (1998, p. 166).

En el marco de la IC, la racionalidad instrumental será el recurso que hará posible la producción y la reproducción continua y masiva de artefactos culturales. Esta racionalidad cristalizará en modelos productivos como la organización planificada y funcional característica de los estudios cinematográficos y musicales, y en la invención y el perfeccionamiento de aparatos como el cinematógrafo, la televisión o las consolas de grabación y reproducción. Esta situación es la que lleva a Adorno a afirmar: "Los interesados en la industria cultural gustan explicarla en términos tecnológicos" (1998, p. 166). Es decir, la novedad y el carácter diferencial del producto radican principal, por no decir exclusivamente, en la calidad del dispositivo tecnológico utilizado para su producción y reproducción, en aspectos como la fidelidad del sonido o la simulación de la percepción de la realidad física, aunque de hecho la historia contada o cantada no varíe en el orden y el sentido de lo ya visto o escuchado: "Con razón el interés de innumerables consumidores se aferra a la técnica, no a los contenidos estereotipadamente repetidos, vaciados de significado y ya prácticamente abandonados" (pp. 180-181).

Este modelo de producción, probado y desarrollado con éxito en industrias como la automovilística, aplicado en la IC dará lugar al surgimiento de un tipo de producto fuertemente convencionalizado. De modo similar a los automóviles, productos intangibles como la música o las ficciones cinematográficas o radiofónicas serán elaborados en serie, de acuerdo con planes administrativos, recursos tecnológicos y humanos disponibles, estándares y esquemas de producción. La técnica y el modelo productivo en serie, que en principio aparecen como instrumentos que afectan el carácter cuantitativo de la producción, no tardan en revelarse como factores que afectan negativamente el carácter

4 En un texto sobre el cine Adorno expuso así su visión de este aspecto de la IC: "The late emergence of film makes it difficult to distinguish between technique and technology as clearly as is possible in music. In music up to the electronic period, the intrinsic technique -the sound structure of the work- was distinct from its performance, the means of reproduction. Film suggests the equation of technique and technology since, as Benjamin observed, the cinema has no original which is then reproduced on a mass scale: the mass product is the thing itself. This equation, however, is problematic, in film as weil as in music. Experts in cinematographic techniques refer to the fact that Chaplin was either unaware of or purposely ignored these techniques, being content with the photographic rendering of sketches, slapstick routines or other performances" (1981- 1982, p. 200). 
cualitativo de los productos. Para Adorno, no se trata solo de producir un número masivo de ejemplares sino también, y sobre todo, de establecer administrativa y técnicamente, a través de fórmulas y recetas, las cualidades de los productos con vistas a su rendimiento financiero, gracias a la previsión de su aceptación masiva, a lo que llama "el primado del efecto". El resultado de este modo de proceder será la elaboración de productos esquemáticos, semejantes: "El esquematismo del procedimiento se manifiesta en que, finalmente, los productos mecánicamente diferenciados se revelan como lo mismo" (1998, p. 168).

Para Adorno este modelo de producción no solo produce artefactos, sino también su propio público, sus propios consumidores. Así el sistema se cierra en su unidad. Los consumidores devienen como un producto más de la técnica, de la razón instrumental, de la ideología del poder. Según Adorno, la producción en serie de la IC al determinar cuantitativa y cualitativamente los productos simultáneamente condiciona y moldea los gustos, las expectativas y la imaginación del público. Si la IC hace circular mayoritariamente lo idéntico y excluye o integra lo extraño, la aceptación en el público de los productos dependerá de los hábitos de consumo que el propio sistema genera y consolida. Para Adorno,

[la industria] lleva a cabo el esquematismo como primer servicio al cliente. [... Para el consumidor no hay nada por clasificar que no haya sido ya anticipado en el esquematismo de la producción. El prosaico arte para el pueblo realiza ese idealismo fantástico que para el crítico iba demasiado lejos. Todo procede de la conciencia: de Malebranche y Berkeley, de la de Dios; en el arte de masas, de la dirección terrena de producción (pp. 169-170).

En otras palabras, Adorno observa en este punto cómo en el orden económico del capital el consumo también es un momento de la producción. El trabajo y el ocio constituyen los dos puntos que al unirse cierran el círculo de la economía y del poder: "La diversión es la prolongación del trabajo bajo el capitalismo tardío" (1998, p. 181). No es que antes del capitalismo no hubiera un tiempo en el cual se suspendiera el trabajo. Lo que Adorno cuestiona es la integración al orden social de ese tiempo, su planificación. El tiempo de descanso será construido dentro de la IC como tiempo para el ocio: espacio que prevé el sistema productivo para que la clase trabajadora consuma lo que ella misma produce: "La diversión, todos los elementos de la industria cultural, se han dado mucho antes que esta. Ahora son retomados desde lo alto y puestos a la altura de los tiempos" (p. 179).

\section{La crítica de Adorno}

Si bien al exponer los elementos que en la teoría de Adorno integran la noción de IC encontramos algunos aspectos de su crítica a la producción industrial de artefactos culturales en los medios masivos de comunicación, su reflexión ahonda en los puntos ya mencionados e incluye otros que hasta ahora no se han tocado aquí. Para empezar, cuando situamos la formación del pensamiento de Adorno en un contexto filosófico y social y en ese marco localizamos el origen de su noción de IC, debemos considerar de qué modo filosofía, sociedad y cultura se encuentran en su reflexión. 
La crítica adorniana al idealismo y en especial su lectura de Hegel, de la cual deriva su singular concepción de la dialéctica -formulada como dialéctica negativa-, en el ámbito social y cultural hallará correlación con lo siguiente: por un lado, con el sentido que Adorno atribuye a la organización de la sociedad tras la emergencia de la burguesía; y por otro, con la defensa que él asume de lo individual y lo singular como un sustrato irreductible de la condición humana. Dicho de otra manera, la crítica de Adorno en el terreno epistemológico a la falsa identidad entre concepto y objeto -identidad construida sobre la premisa de la supremacía del sujeto- en el terreno social y cultural se traduce en la crítica a la violencia que el poder ejerce sobre los individuos al concebirlos y tratarlos no como seres singulares, sino como ejemplares idénticos de un modelo establecido por la racionalidad instrumental. Así se encuentran epistemología y filosofía de la sociedad y la cultura, al mostrar cómo en ambos dominios ha prevalecido el poder identificador de la razón, expresado en la tendencia a construir sistemas en los cuales la totalidad se impone sobre la particularidad. Y es en la formación de este tipo de estructuras donde Adorno ve que los poderes económico y político se encuentran, al determinar desde sus lógicas la organización social y una tipología de cultura: "La desconsiderada unidad de la industria cultural da testimonio de la que se cierne sobre la vida política" (1998, p. 168). La vida se torna en un molde por llenar: "La unidad visible de macrocosmos y microcosmos muestra a los hombres el modelo de su cultura: la falsa identidad de universal y particular" (p. 166).

Es por este camino que para Adorno se revelará la coincidencia entre las pretensiones totalitarias de regímenes como el nazi y el estalinista y del capitalismo en su forma más perfeccionada. Finalmente, uno y otro modelo de organización social, aunque se inscriban en ideologías políticas diferentes, coincidirán en su voluntad de dominio, en la instrumentalización de la razón y en el oscurecimiento de la individualidad. Por eso, para Adorno, la identidad entre lo universal y lo particular se dará como falsa, ideológica.

Es en ese marco donde la IC se entenderá como concreción de una racionalidad que busca igualarlo todo, desde sus productos hasta los consumidores de estos, dentro de un esquema en el que solo se reconoce lo útil a la reproducción de un orden social. Para Adorno, la violencia física y el terror que regímenes totalitarios, como los nazis y el estalinista, utilizaron para modelar y ajustar a los individuos al orden total hallan equivalencia en la sociedad liberal y democrática en la homogeneización de la producción cultural de los medios y de las subjetividades de quienes consumen tales productos. Como es evidente, este hecho, además de facilitar la reproducción del orden de las cosas, afectará a la producción cultural y a los individuos.

Veamos, en primer lugar, cómo afecta entonces según Adorno la IC la producción cultural. Este es uno de los puntos centrales de su argumentación, pues aquí se revelan algunas de las premisas de su pensamiento estético. Como hemos observado, la noción de IC refiere la producción de artefactos para medios masivos de comunicación. Para Adorno, los artefactos hechos para los medios constituyen un tipo de producción estética que no se da como arte. La relación medios-arte parece inviable para el arte: "El cine y la radio no necesitan ya darse como arte. La verdad de que no son sino negocio les sirve de ideología que debe legitimar la porquería que producen deliberadamente" (1998, p. 
166). Hay aquí, al menos, dos cuestiones importantes: primera, la producción cultural de los medios es confrontada con y valorada desde un concepto de arte, y como veremos luego no con cualquier arte ni con un concepto plano de arte; así se establece una suerte de ecuación en la cual un tipo de arte y un tipo de producción cultural que le es opuesta se constituyen en modelos de dos concepciones de cultura; segunda: la producción de la IC no es arte, es solo negocio.

En cuanto Adorno valora la producción de la IC fundamentalmente como negocio, todos los artefactos producidos dentro de su sistema o integrados a él adquieren el único estatus de mercancía. El valor de uso, que Benjamin había leído como valor de exhibición, se impondrá sobre otros aspectos y usos sociales de la producción cultural, pero que ahora la función de los artefactos culturales no derivará de una necesidad primaria, sino de las necesidades creadas en la segunda naturaleza constituida por el orden económico y social:

El contraste técnico entre pocos centros de producción y una dispersa recepción condicionaría la organización y planificación por parte de los detentores. Los estándares habrían surgido en un comienzo de las necesidades de los consumidores: de ahí que fueran aceptados sin oposición. Y, en realidad, es en el círculo de manipulación y de necesidad que la refuerza donde la unidad del sistema se afianza cada vez más (1998, p. 166).

Finalmente, el interés de lucro y el poder del dinero decidirán sobre la producción cultural, es decir, el devenir de los artefactos culturales desde su concepción hasta sus procesos de circulación y consumo como pura mercancía decidirá sobre su carácter de arte. Lo que aquí está en juego es uno de los pilares de la estética de Adorno: el carácter dual del arte, esto es, como autonomía y como fait social. Lo que para Adorno sacrifica la producción cultural dentro de la IC, que como vemos en este contexto hace referencia fundamentalmente al arte, es su autonomía, el rechazo del artefacto artístico de cualquier lógica que no sea aquella emanada de su propio mundo, de sus impulsos miméticos. La defensa en la estética de Adorno de la autonomía del arte -que finalmente guarda en su fondo una ética no concretada en la historia sino en la estética- lo lleva a refutar el carácter artístico de los productos de la IC.

Hay que destacar que en el pensamiento de Adorno el concepto de arte proviene de lo que él llama la modernidad radical. O sea, el arte moderno en dos de sus expresiones más acabadas: la música y la literatura, representadas en la producción de autores como Schönberg, Berg, Kafka y Beckett. Sí, aquí se ponen en juego comparaciones como, por ejemplo, entre El innombrable y El viejo y el mar, o Pierrot lunaire y Mack the knife. Evidentemente, al confrontar ese modelo de producción artística y de productos estéticos con productos elaborados dentro de otro modelo estos últimos van a mostrarse como radicalmente diferentes. Adorno expresará esta diferencia introduciendo la distinción entre arte serio o auténtico y arte de masas, de entretenimiento o ligero. Y si el arte serio lo encarnan la música y la literatura modernas, el arte ligero lo representan el cine, la televisión y la música que se reproduce en la radio. A diferencia del arte serio, para Adorno las películas, las series de televisión, los programas radiofónicos y las canciones que se pasan por la radio no son autónomos, son solo negocio e instrumentos útiles a la reproducción de la ideología capitalista. Arte y diversión, para Adorno, son irreconciliables: "Pero lo nuevo 
está en que los elementos irreconciliables de la cultura, arte y diversión, son reducidos, mediante su subordinación al fin, a un único falso denominador: a la totalidad de la industria cultural" (1998, p. 180).

La escisión entre un arte autónomo, auténtico y serio, y otro al cual sí se le reconoce un estatus parecido solo es como arte heterónomo, falso y ligero es uno de los contenidos más criticados del pensamiento de Adorno ${ }^{5}$. La diferenciación, sin embargo, como es frecuente en la filosofía de Adorno trasciende el marco donde se formula y hace necesario, para comprenderla, -y también para trazarle límites- observar la relación que tiene con el contexto general de su pensamiento y del momento histórico en el que fue formulada. No podemos ignorar que la estética de Adorno guarda una estrecha relación con sus posiciones epistemológicas y morales, y con su concepción de la relación del arte con la memoria y la historia.

Recordemos que Adorno escribe en y sobre la posguerra. La primera versión de Dialéctica de la Ilustración es de 1944, es decir, que fue pensada durante la guerra, en el exilio. Adorno apreció en el arte moderno una producción estética que, afianzada en su autonomía, se manifestaba como un reducto, quizá el último, de la autonomía del espíritu. La autonomía del espíritu aniquilada por la historia, ya fuera en la forma de la eliminación física de las personas o de la alienación de las conciencias, todavía se muestra como posible - de ahí su valor utópico- en el arte más radical. Y este arte, para Adorno, preserva una imagen de la autonomía tomando como material, como en los casos de Kafka y de Beckett, precisamente las ruinas producidas por la razón instrumental y la memoria de los aniquilados por el poder. Arte serio también es arte grave, el arte que según la Teoría estética, escrita casi veinte años después del ensayo sobre La industria cultural, habla el lenguaje del sufrimiento. Es un arte que hace suya la culpa de la barbarie ${ }^{6}$. Para Adorno,

5 La tendencia de esta crítica, al menos desde la perspectiva de la sociología y los estudios culturales, se puede ejemplificar con Martín-Barbero: "Sabemos que la crítica del goce tiene razones no solo estéticas. Los populismos, fascistas o no, han predicado siempre las excelencias del realismo y han exigido a los artistas obras que transparenten los significados y que conecten directamente con la sensibilidad popular. Pero la crítica de Adorno, hablando de eso, apunta sin embargo hacia otro lado. Huele demasiado a un aristocratismo cultural que se niega a aceptar la existencia de una pluralidad de experiencias estéticas, una pluralidad de los modos de hacer y usar socialmente el arte" (Martín-Barbero, 2003, p. 59). Como expongo en este texto, considero que por su concepción del arte Adorno restringe el ámbito del arte y de la experiencia estética. Estoy de acuerdo en que las preferencias de Adorno se corresponden con el arte de la tradición de Europa occidental, pero no creo que su posición quede aclarada por encuadrar su planteamiento en un mero aristocratismo cultural, pues ello no tiene en cuenta la imbricada relación entre arte, memoria, moral, resistencia y utopía presente en el pensamiento estético adorniano.

6 Así lo expresa Adorno en uno de tantos lugares donde consigna este pensamiento: "Allá donde hoy en día aparece la jovialidad, está distorsionada en cuanto ordenada, hasta el ominoso tanto da de esa tragicidad que se consuela con que la vida es así. El arte, que ya no es en absoluto posible sino como reflexivo, debe renunciar por sí a la jovialidad. A ello le obliga sobre todo el pasado reciente. La frase de que después de Auschwitz ya no se puede escribir ningún poema carece de validez tomada tal cual, pero es cierto que después de eso, porque fue posible y porque resulta indefinidamente posible, ya no se puede imaginar ningún arte jovial. Objetivamente degenera en cinismo, por mucho que confíe en la bondad de la comprensión humana. Por lo demás, tal imposibilidad fue sentida por la gran poesía, en primer lugar sin duda en Baudelaire, casi un siglo antes de la catástrofe europea" (2003, p. 583). 
al dar expresión al sufrimiento, este arte es un modelo de resistencia, de negatividad, por cuanto no se sirve de las fórmulas y las recetas establecidas por el pensamiento funcional, porque al formarse desde su propia lógica se resiste críticamente a la lógica del dominio. De esta manera, al acoger el dolor y el sufrimiento producidos por la violencia del pensamiento que identifica e iguala lo singular subsumiéndolo en principios abstractos y universales, la experiencia estética que este tipo de arte produce hace sentir, como una suerte de dolor en el plano cognoscitivo, un reflejo del dolor que la lógica del dominio inflige a los individuos.

Para Adorno, el arte ligero y de entretenimiento, que es un producto industrial, al ceder en su autonomía se pone de espaldas a la historia y a la memoria, se hace instrumento de adaptación: "en tanto que ocupación del tiempo libre, el arte tiene que ser cómodo y no vinculante" (2004, p. 311). A diferencia del arte moderno, el arte de masas no ofrece resistencia, su experiencia no produce un shock cognitivo ni pone a prueba la lógica convencional del mundo. Al actuar así, este arte pacta con lo establecido y hegemónico.

La distinción entre arte de masas y arte serio implica, además, otro elemento fundamental: la cuestión de la técnica. Para Adorno el arte moderno tiene un carácter ejemplar porque en él la técnica artística -que es un modo especial de la técnica- se presenta como un correctivo de la técnica instrumental. Para él, tal como se despliega en el arte moderno la técnica artística respeta la naturaleza del objeto y no lo violenta para formarlo ajustado a los conceptos generales establecidos por una racionalidad funcional. Todo ese apartado de la estética de Adorno implica su teoría de la mimesis, la cual se puede entender como un modo de relación respetuosa de la razón con lo que le es externo, es decir, dar primacía y brindar reconocimiento al objeto en su singularidad. Precisamente esto lo haría posible la racionalidad estética. Y es ese carácter de la racionalidad el que, para Adorno, se pierde en la producción de la IC. En ella el producto estético no es singular, es un producto típico y serial. En este caso la técnica no se ajusta a las exigencias formales del producto en desarrollo, a sus impulsos miméticos, sino a un plan y a una razón calculadora que desde el inicio diseña estratégicamente la obra acorde con la lógica del sistema de la IC.

En este lugar volvemos a encontrar que técnica y tecnología reaparecen cargadas de un matiz funcional. En la producción de la IC no se da la experiencia del artista como mediador para que la obra singular alcance la existencia. La técnica artística es sustituida por la planificación, la administración, la inserción del producto en el orden más amplio de los negocios que giran a su alrededor, y por el trabajo de secciones o departamentos encargados de funciones específicas. Y es ahí donde, por otra parte, la tecnología da cuerpo a la técnica en forma de aparatos. Si, en principio, la tecnificación de la producción en su forma de planificación permite establecer estereotipos, clichés, géneros y estilos que afectan en su carácter cualitativo a los productos estéticos, la tecnología facilitará mediante los medios de producción y reproducción en masa la multiplicación constante de artefactos estéticos altamente planificados. 
Por otra parte, es necesario volver sobre un aspecto de la IC considerado más arriba pero que merece una ampliación. Si bien en Adorno la distinción entre arte serio y arte ligero se presenta irreductible, la concepción de la IC como un sistema que absorbe e integra lo extraño como elemento exótico se hace extensiva al arte, producido fuera de la lógica del sistema. El arte que resiste y que acoge el dolor también tiene un lugar previsto en el orden total: ya sea en el mercado de las novedades o en las instituciones que forman los cánones particulares de las distintas formas de arte, como el museo. Para Adorno este hecho es inevitable porque la producción artística, en cuanto fait social, tiende a la sociedad. En la Teoría estética Adorno expone esta idea diciendo que "el arte (incluso el más avanzado) tiene en sí la tendencia a su socialización, a su integración social" (2004, p. 302). Esta socialización es la integración social del arte es través del proceso de circulación y recepción en el cual la obra queda subsumida a la totalidad: a la institución social y económica que acoge la obra y al sentido que desde allí se le asigna. Lo que alguna vez fue disonante y negativo acaba absorbido: "Por lo general, la recepción desgasta lo que en el arte era la negación determinada de la sociedad. Las obras suelen actuar críticamente en el momento de su aparición; más tarde quedan neutralizadas debido al cambio de la situación" (p. 302). Observemos que Adorno habla de "neutralización". La cuestión es importante porque Adorno describe aquí una suerte de domesticación de las obras de arte más radicales. Incluso el arte más intransigente con la sociedad es incorporado a ella. Recordemos, por ejemplo, que Hollywood tiene su propia ala progre y crítica.

A la cuestión del arte en la IC, como también se apuntó más atrás, le es inherente el posicionamiento de un tipo de arte como modelo de cultura. Por un lado, según vimos, están el arte ligero y su público. El arte de masas es valorado como un arte heterónomo, carente de criticidad y de resistencia frente a la totalidad. Y el consumo de los productos de los medios masivos es definido como la aceptación de la lógica de la producción, por lo tanto es entendido como reproducción de la lógica del dominio en la cultura producida por la IC. En Adorno, la concepción de los consumidores del arte de masas es la de seres pasivos, cooptados totalmente por el sistema o en busca de evasión, a través de los productos de la IC, del agobio que produce el mundo. La diversión es vía de escape: "Es buscada por quien quiere sustraerse al proceso de trabajo mecanizado para poder estar de nuevo a su altura, en condiciones de afrontarlo [...] Del proceso de trabajo en la fábrica y en la oficina solo es posible escapar adaptándose en él al ocio. De este vicio adolece, incurablemente, toda diversión" (1998, p. 181).

Desde esa doble perspectiva -la integrada por los medios masivos y su producción, y por el tipo de sujeto encarnado en el consumidor de tales productos-, la cultura producida por el sistema de la IC es una cultura uniforme: "Toda cultura de masas bajo el monopolio es idéntica" (1998, p. 167). Se trata de una concepción de la cultura en la que los productos y los individuos, estos últimos un producto más, son piezas funcionales dentro del sistema. Aunque se muestre como una cultura del bienestar y de oportunidades, es una cultura instrumentalizada por el poder económico, útil a él. Desde este punto de vista, la IC y el arte de masas como su principal creación producen una cultura falsa. Por esa misma razón, Adorno comienza su ensayo sobre la industria cultural afirmando que la dispersión 
a la cual dio lugar la extrema especialización del mundo moderno, en lugar de introducir caos, produjo un orden homogéneo, el de la cultura de masas: "La tesis sociológica según la cual la pérdida de apoyo en la religión objetiva, la disolución de los últimos residuos precapitalistas, la diferenciación técnica y social y la extremada especialización han dado lugar a un caos cultural, se ve diariamente desmentida por los hechos. La cultura marca hoy todo con un rasgo de semejanza" (p. 165).

En sentido contrario, el arte moderno, pensado como escenario donde se refugia la autonomía del espíritu, es posicionado como imagen de una cultura de la resistencia, de la autonomía y de la libertad. La dicotomía arte serio-arte ligero sirve de base a la diferenciación entre una cultura autónoma y una cultura prefabricada. La asociación, por una parte, del arte moderno con la libertad y la negatividad del espíritu y, por otra, del arte de masas con la declinación de la autonomía y la reproducción de la lógica del dominio no solo opone dos tipos de producción estética, sino también dos modos de estar en el mundo:

El imperativo categórico de la industria cultural no tiene nada que ver con la libertad, a diferencia del imperativo categórico de Kant. Dice así: «Acomódate, aunque no sepas a qué; acomódate a lo que existe y a lo que todos piensan como reflejo del poder y la omnipresencia de lo que existe». Mediante la ideología de la industria cultural la adaptación sustituye a la consciencia (2008, p. 300).

Sin embargo, puesto en otros términos, al caracterizar al arte serio como arte auténtico y al arte ligero como arte de pacotilla, inevitablemente los modelos de cultura derivados de ellos arrastran el peso de los calificativos que portan.

\section{Conclusiones: Crítica y actualidad de la noción}

Emitir un juicio crítico sobre los planteamientos de Adorno resulta una tarea difícil y compleja, por lo menos, por dos razones; una, porque en un mundo globalizado y en un Estado y unas tradiciones políticas, en particular como la colombiana, determinados por el poder y los intereses económicos, se hace imposible no reconocer la pertinencia y la vigencia del planteamiento de Adorno acerca del modo como bajo el primado del capital la sociedad y la cultura han sido enmarcadas dentro de un sistema; y dos, por la manera como Adorno construye y expone su reflexión, pues cuando algunos pasajes de su teoría se toman de manera aislada fácilmente se puede incurrir en una fragmentación forzada que mutila la trama de su pensamiento.

Aún así, al planteamiento de Adorno sobre la IC se le pueden señalar algunos límites. La posición teórica y estética de Adorno, a mi juicio, se construye desde dos columnas fundamentales: la perspectiva de la crítica socioeconómica y la del tipo de experiencia estética que produce el encuentro con un tipo particular de arte. Esto no excluye, como se expuso más atrás, que a estas perspectivas se sumen elementos importantes de otras dimensiones del pensamiento de Adorno, como son su visión de la historia, la moral o la teoría del conocimiento. Sin embargo, si se acepta que su crítica parte principalmen- 
te -aunque no se queda ahí- de una visión socioeconómica y de un concepto de arte, podremos anotar dónde encuentra algunos límites su planteamiento.

Por lo visto, considerar que solo un purismo estético asiste a Adorno para tomar partido por el arte moderno con respecto al arte de masas es no tener en cuenta algunos elementos decisivos que atraviesan todo su pensamiento. A pesar del dejo kantiano que subsiste en su estética, Adorno no articula un concepto del arte fundado sobre un distanciamiento estético a ultranza de la historia, sobre un juicio de gusto que estime cuál es el buen o mal gusto asociado a cada tipo de arte. Es indiscutible que la reelaboración de Adorno sobre la teoría kantiana del desinterés como materia de lo que se juzga bello resulta compleja, pues esta estética parte de que lo que hace interesante y de algún modo útil al arte es su falta de utilidad. Igualmente es indiscutible el tono despectivo con el que Adorno califica "la porquería" que produce la IC. Cierto es, además, que el arte moderno se inserta en la tradición del arte burgués, que es precisamente en la cual Adorno se formó y en la cual se inscribió como sujeto social. No resulta entonces apresurado pensar que su afinidad con este arte le haya impedido ver y pensar el arte de masas y las modalidades de experiencia estética que este procura desde otras perspectivas. No es difícil asignarle un tufillo aristocrático a sus preferencias artísticas. Pero atribuir su posición sobre el arte solo a un gusto de aristócrata es reducir su pensamiento. Adorno aclaró que lo que él llamó IC surgía de un proceso de planificación y cálculo, que no respondía a una formación espontánea:

La expresión «industria cultural» parece haber sido empleada por primera vez en el libro Dialéctica de la Ilustración, que Horkheimer y yo publicamos por primera vez en 1947 en Ámsterdam. En nuestros borradores hablábamos de «cultura de masas». Pero sustituimos esta expresión por «industria cultural» para evitar la interpretación que agrada a los defensores de la causa: que se trata de una cultura que asciende espontáneamente desde las masas, de la figura actual del arte popular. La industria cultural es completamente diferente de esto, pues reúne cosas conocidas y les da una cualidad nueva. En todos sus sectores fabrica de una manera más o menos planificada unos productos que están pensados para ser consumidos por las masas y que en buena medida determinan este consumo (2008, p. 295).

En la filosofía de Adorno la cuestión medular está en la posición que el arte adopta frente a la totalidad y la omnipotencia alcanzada por algunas formas de poder, lo cual, por otra parte, no significa necesariamente que la única forma de adoptar una posición frente al sistema sea chocar con él, refugiarse en el hermetismo y cortar la comunicación con el mundo, o que desde el propio mundo de la IC no se pueda exponer su funcionamiento.

La postura de Adorno condiciona que vea los productos de la IC fundamentalmente como negocio. En este texto no se pone en discusión el hecho de que la IC conciba artefactos destinados a producir ganancia, que sea desvelado el carácter de mercancía de sus productos. Adorno tiene mérito en mostrar que en el capitalismo no solo los bienes útiles, en un sentido material y funcional, son mercancías. También es revestida con este carácter la producción cuyo contenido se consume en la experiencia que proporciona el acceso a un producto o a través de la información obtenida de él. El componente estético de la 
doble perspectiva de Adorno agrega un aspecto decisivo en su diagnóstico: aquello que caracterizaría a la modernidad artística radical, su autonomía, que para Adorno cristaliza en el hermetismo de las obras que hablan una lengua desconocida, es el criterio desde el cual él valora los productos de la IC. Si bien el arte moderno en cuanto fait social es mercancía, trasciende esta condición gracias a su autonomía. El arte ligero, en cambio, carece ella. Por eso para Adorno todo lo que produce la IC es solo negocio, sus productos no son arte. Si acaso, son una parodia del arte. De esta manera, Adorno construye una noción reacia a considerar la producción de la IC desde otros ángulos. ¿̇Todo en la IC es mercancía pura, un cascarón que siempre contiene lo mismo? ¿No tiene límites el concepto de arte aplicado por Adorno? Aunque expandibles porque la estética de Adorno ayuda a comprender aspectos del arte hecho después de la elaboración de su pensamiento estético, los límites de su teoría están dados por su marca de origen. Como en su estética Adorno pone un marcado énfasis en la noción de forma, en la IC se presta atención sobre todo a las fórmulas y los clichés de sus productos. No le falta razón a Adorno en ello, pero su posición analítica, contrario a lo que fija su propio método dialéctico, lo lleva a formular un juicio general y categórico que termina por adquirir el carácter de eso que él combatió con su pensamiento: el prejuicio. Como afirma Douglas Kellner:

Arguing that all popular music is "so completely identical" might have some validity in the analysis of the radio-based popular music of the day, although on the whole it violates Adorno's own defense of particularity and critique of identity-thinking which subsumes heterogeneous particulars to abstract categories. The classical critical theory approach, especially Adorno's work, generally limits itself to attacking the ideology and purely retrogressive effects of radio, popular music, films, television, and so on. [...] Part of the problem is that for Adorno the artifacts of the culture industry are simply beneath contempt (2002, p. 101) ${ }^{7}$.

Adorno pocas veces se detiene en las peculiaridades y las diferencias que se pueden encontrar incluso en los productos de la IC. Cuando se ocupa de estos productos, como en el caso de sus estudios sobre la televisión, se hace cargo de la producción más estandarizada y estereotipada. No analiza con cuidado, por ejemplo, que aparte de la determinación económica la propia IC también establece sus lógicas y sus propios valores estéticos, entre los cuales, del mismo modo que en el mundo del arte consagrado, operan esquemas de jerarquización y canonización.

En sentido similar, la generalización de su concepto hace que los medios surgidos con los desarrollos tecnológicos de la época -radio, cine, televisión-sean considerados

$7 \quad$ Martín-Barbero se pronuncia en sentido similar, al advertir que la concepción de la industria cultural como sistema es pertinente pero se hace excesiva: "La afirmación de la unidad del sistema constituye uno de los aportes más válidos de la obra de Horkheimer y Adorno, pero también de los más polémicos. Por una parte, la afirmación de esa unidad revela la falacia de cualquier culturalismo al ponernos en la pista de «la unidad en formación de la política» y descubrirnos que las diferencias pueden también ser producidas. Pero esa afirmación de la «unidad» se torna teóricamente abusiva y políticamente peligrosa cuando de ella se concluye la totalización de la que se infiere que del filme más ramplón a los de Chaplin o Welles «todos los filmes dicen lo mismo», pues aquello de lo que hablan «no es más que el triunfo del capital invertido»” (2003, p. 54). 
solo desde la peculiaridad de su configuración y uso social en Estados Unidos. Dicho de otra manera: por lo que respecta a su relación con el orden social y económico del capitalismo avanzado, la noción de IC se construye en la constelación histórica que posibilitó el desarrollo de los mass media en la sociedad estadounidense. Quizá esta precisión, ya implícita al describir el contexto social donde Adorno elabora su noción, delimite mejor el alcance del concepto: por lo que respecta a su inserción en el orden económico, la noción de IC refiere el modelo de producción industrial de cine, música e información de entretenimiento a la manera de las grandes majors y estudios de California. Para Adorno, cine es sinónimo de Hollywood. Su diagnóstico sobre Hollywood es acertado, pero parcial. Tomar a Hollywood como equivalente del cine es limitado. Ya antes de su ensayo de 1947 y después de él, había otras cinematografías que mostraban otras facetas del cine, incluso próximas al pensamiento estético de Adorno.

Cine, radio, televisión e impresos son los medios que en Adorno integran la IC. Todos, salvo la imprenta, son desarrollos tecnológicos característicos del siglo XX, de la era industrial. Por esto, y por el lugar que concede a la técnica artística cuando habla del arte moderno a diferencia del lugar que le otorga en la IC, parece como si Adorno despreciara la tecnología y la señalara como determinante de la pérdida de la autonomía del arte. Es inocultable que en su pensamiento la técnica y la tecnología no salen bien libradas. Sin embargo, no se puede olvidar que en el ensayo sobre La industria cultural, Adorno precisa que no es la técnica en cuanto tal la que determina ese comportamiento, sino la función que se le asigna en el sistema:

Por el momento, la técnica de la industria cultural ha llevado solo a la estandarización y a la producción en serie y ha sacrificado aquello por lo cual la lógica de la obra se diferenciaba de la lógica del sistema social. Pero ello no se debe atribuir a una ley de desarrollo de la técnica como tal, sino a su función en la economía actual (1998, p. 166).

Por otra parte, la perspectiva estética de Adorno, tan decisiva e influyente para dar sentido a parte de la producción artística moderna e incluso contemporánea, determina que su idea de arte y de experiencia estética no se pregunte en términos diferentes sobre el carácter de los productos inscritos en la IC. Condicionar, como parece derivarse de su estética, prácticamente la idea de autonomía a la obra única y a la producción artística individual, como puede ser la del escritor o el compositor musical, resulta problemático. Ni la producción de un ejemplar único ni el trabajo individual de un artista garantizan la autonomía de su producto y de su quehacer. Eso lo advierte el propio Adorno en su Teoría estética. Y por lo que respecta a la singularidad de la obra, este carácter puede estar dado aun cuando el producto sea elaborado por un grupo de artistas con medios de reproducción técnicos o electrónicos, como en el caso del cine, el vídeo o las, hoy llamadas, nuevas músicas. Adorno no discute en su escrito de 1947 si los espacios estéticos abiertos con la radio, el cine y la televisión pueden dar lugar a producciones singulares. Esto es, no deja en suspenso la generalización determinista de que radio, cine y televisión están dados solo como negocio y porquería estética ${ }^{8}$. Con todo, cabe decir que Adorno le sale al paso

8 En este sentido, Martín-Barbero anota que uno de los cambios operados en la noción de industria cultural se localiza en los años sesenta en la lectura que Edgar Morin hace de la teoría de Adorno y Horkheimer: 
a este modo de leer su pensamiento cuando, en el Resumen sobre la industria cultural, anota que el término industria refiere a la estandarización del producto y no estrictamente al proceso de producción de los artistas.

En una dirección próxima -y en esto se aprecia una de las diferencias fundamentales entre Benjamin y Adorno-, esta cuestión contiene la pregunta por el alcance del concepto de arte de Adorno para pensar la producción y la experiencia estéticas adscritas a la IC. La salida de Adorno, vimos, fue establecer la dicotomía entre arte serio y arte ligero. Esta clasificación ha dado lugar a que desde la sociología y los estudios culturales se acuse a Adorno de fundar desde la estética una distinción que tras la diferencia entre gustos serios y ligeros alberga una distinción de clase. La clasificación de Adorno, sin duda, hoy resulta discutible e insatisfactoria pues, más allá de sus posibles implicaciones sociológicas, su respuesta sobre el arte en la IC es un juicio al arte de masas desde el concepto de arte construido alrededor del arte moderno. Sin embargo, cel único modelo de experiencia estética admisible es el de aquella que proporciona el arte moderno en su expresión más radical? ¿Este concepto de arte debe ser normativo para toda la producción estética?

Si bien Adorno tenía una clara concepción histórica del arte, y su teoría del arte se localiza en un momento histórico preciso, su compromiso ético lo condujo a un punto de radicalidad. Por eso, aunque no haya sido escrita con espíritu normativo, su teoría del arte a veces se torna inflexible. El componente crítico, histórico y moral del pensamiento de Adorno nos persuaden de su lectura sobre un arte como el de Beckett, pero ello no excluye que pueda haber otro tipo de experiencias y de manifestaciones estéticas. Tomar a este respecto la teoría de Adorno como un principio inamovible por la fuerza y las razones históricas que lo asisten puede impedir considerar, como él mismo lo sugirió, que también puede haber otras formas, distintas del hermetismo de la modernidad radical, del arte concretarse sin que necesariamente se ponga de espaldas a la historia y a la memoria. Adorno señaló que podría haber un arte que diera voz de otro modo al ideal de lo negro: "Tal vez, los jugueteos habituales con los colores y los sonidos reaccionen al empobrecimiento que ese ideal trae consigo; tal vez, el arte derogue alguna vez sin traición ese precepto" (2004, p. 60).

En el mismo orden de ideas, la concepción que Adorno expone del receptor resulta, como mínimo, desproporcionada, si no presa de un prejuicio. Decir que un producto típico de Hollywood o una canción pop no estimulan la reflexión y la crítica puede ser cierto, pero no lo es siempre. Puede que no las fomenten del modo como el pensamiento crítico de Adorno las concibe, por cuanto sus formas no desafían nuestra estructura de la comprensión. Sin embargo, sus contenidos, e incluso algunas veces sus formas, sobre todo en el cine, sí son portadoras de sentido crítico. Igualmente, señalar que el consumo

\footnotetext{
"Con una ganancia que venía no solo de la descripción socioeconómica del proceso tanto del lado de los productores como de los consumidores, sino de la negación a fatalizar el cambio desmontando así uno de los malentendidos más tenaces del pensamiento de Horkheimer y Adorno: el de que algo no podía ser arte si era industria. Morin demuestra, a propósito del cine especialmente, cómo la división del trabajo y la mediación tecnológica no son incompatibles con la «creación» artística; es más, cómo incluso cierta estandarización no entraña la total anulación de la tensión creadora" (2003, p. 73).
} 
de los productos de la IC disminuye la capacidad crítica es hacer depender el desarrollo de esta capacidad si no exclusiva al menos principalmente del ámbito de este tipo de producción cultural9.

Uno de los aspectos más problemáticos de la noción de IC se desprende también de la aplicación de la concepción del arte de Adorno. Aquí, repito, no pongo en cuestión la pertinencia del pensamiento de Adorno sobre el arte moderno. La cuestión discutible es su extensión como criterio decisivo sobre un tipo de producción estética diferente, que coexistió con el momento histórico del arte moderno, y su implicación en lo que respecta a la construcción de una tipología cultural. Como quedó dicho, el concepto de arte sirve de modelo para pensar un modelo de cultura. En este sentido, como han sugerido algunos comentaristas, el modelo de cultura de Adorno puede quedar "atrapado" en su concepto de $\operatorname{arte}^{10}$. La diferenciación entre arte serio y arte ligero trae consigo, a su vez, dos tipos de producción cultural y, por lo tanto, dos tipos de cultura. La cultura, entonces, se concibe desde el arte. De esta manera, al formular la crítica cultural desde la estética la visión resulta limitada, por ejemplo, al confrontarse con una visión antropológica de la cultura. Desde luego que la cultura es más que el arte. En Adorno, la industria cultural produce artefactos de carácter estético, el arte es producido industrialmente. La cultura, entonces, parece circunscrita al arte:

In a sense, Adorno's aesthetics are undialectical. He operates with a binary contrast between "authentic" art and mass culture in which the latter is primarily debased and emancipatory effects are limited to the former. This stance reproduces the German religion of high art and its inevitable elitism, and completely excludes the "popular" from the domain of "the authentic," thus regressing behind the critiques of Brecht and Benjamin - and Adorno's own critique of "the authentic" in his book Jargon of Authenticity (Kellner, 2001, p. 105).

9 En su examen filosófico al arte de masas, Noël Carroll revisa los, a su juicio, principales argumentos que Adorno y Horkheimer oponen a la industria cultural. Tras señalar los elementos que la crítica de los de Frankfurt comparten con otros autores, como los de la masificación y la fórmula, Carroll llama la atención sobre el carácter social y político de la posición de Adorno y Horkheimer. En ese contexto, distingue tres ejes de la crítica: "El argumento de la libertad, el argumento de la susceptibilidad y el argumento del condicionamiento". Y luego de descomponerlos uno por uno de acuerdo con lo que en su lectura constituye los ingredientes de cada argumento, Carroll los objeta mostrando un acento generalizador e incongruencias entre premisas y conclusiones en los planteos de los frankfurtianos. Por ejemplo: "No sirve decir que Adorno y Horkheimer entendían que cierto arte de masas perjudica la imaginación, ya que, en la medida en que hay obras que no lo hacen, no se encuentran ya en posición de rechazar el arte de masas o, como ellos dicen, la industria cultural" (2002, pp. 74-88).

10 Un ejemplo de ello lo constituye la reelaboración del concepto de industria cultural que propone Daniel Mato. Desde una visión socioantropológica del asunto, este autor amplía la noción de cultura y la saca del ámbito del arte para referir así con la industria cultural la producción planificada de prácticamente toda suerte de bienes y servicios cargados desde el origen con significados predeterminados: "Pienso que su idea [la de IC de Adorno y Horkheimerl quedó relativamente atrapada dentro del contraste con la idea de arte, y que esta marca de origen explica, al menos en parte, las limitaciones en el campo de aplicaciones de la idea de «industria cultural»" (2007, p. 134). Posiciones como la de Mato han dado lugar a la acuñación de una categoría alternativa a la de Adorno, carente sin embargo de carácter crítico y polémico y cargada sobre todo de un valor funcional y economicista, como es la de "industrias del entretenimiento y la diversión" o "industrias creativas". Al respecto remito a Enrique Bustamante (ed.) Industrias creativas (2011). 
Hay que agregar que la reflexión de Adorno sobre el arte en la IC, además de la producción, considera la recepción. Por esta vía el consumidor viene a ser el modelo del tipo de individuo que produce la sociedad en la cual se desarrolla la IC. Así las cosas, la pasividad, la atrofia de la imaginación, la ausencia de sentido crítico y el infantilismo atribuidos por Adorno a los consumidores del arte de masas son transferidos del plano estético a la generalidad de la subjetividad característica de la sociedad y la cultura del periodo industrial. Pregunta inevitable: ¿esto necesariamente es así?

Quizá la crítica a Adorno pueda agregar otro elemento en el hecho de que al ser formulado su pensamiento desde el arte, la trascendencia de la esfera estética al plano de la acción solo se presenta como apariencia y utopía. Tomar el sentido que Adorno atribuye al arte moderno como modelo de cultura, por lo tanto, es proponer también un modelo de cultura utópico.

Ahora bien, plantear una crítica a la noción de IC de Adorno no puede ignorar algunas ideas suyas presentes en textos que no tienen el reconocimiento de La industria cultural o de la Teoría estética. Puesto que el arte y la industria cultural fueron dos de los leit motivs de su reflexión, en distintos momentos Adorno volvió sobre sus planteamientos y, conservando la fuerza de algunas tesis que aquí han sido puestas en cuestión, en algunos casos dio lugar a la posibilidad de que aquellas prácticas estéticas surgidas en y explotadas por la IC pudieran tomar distancia de ella y desarrollar su potencial artístico. Adorno, por ejemplo, llegó a reconocer el potencial educativo de la televisión, utilizó la radio para difundir su pensamiento y, siempre dentro de su concepto de arte eso sí, señaló cuándo el cine podría alcanzar el estatuto artístico. A este último lo reconoció como un espacio de creación que distanciado del sometimiento al cual lo redujo la IC se mostraba como arte: "Irrespective of the technological origins of the cinema, the aesthetics of film will do better to base itself on a subjective mode of experiencie which film resembles and which constitutes its artistics character" (1981-1982, p. 201).

Para Adorno, en un cine hecho de espaldas a la profesionalización de Hollywood podría estar la esperanza de una producción cinematográfica diferente de la IC: "In this comparatively awkward and unprofessional cinema, uncertain of its effects, is inscribed the hope that de so-called mass media might eventually become something qualitatively different" (p. 199). En este sentido, puesto que Adorno leyó la imagen cinematográfica de la IC fundamentalmente en su carácter indicativo y narrativo, para él cuando el cine se dejara llevar por sus impulsos miméticos y rompiera con el esquematismo planificador llegaría a ser arte, establecería una estrecha relación con su concepto de belleza natural:

These images [como las del sueño] do not emerge into one another in a continuous flow, but are rather set off against each other in the course of their appearance, much like the magic lantern of slides of our chidlhood. It is in the discontinuity of their movement that the images of the interior monologue resemble the phenomenon of writing: the lattern similarly moving before our eyes while fixed in its discrete sings. Such movements of interior images may be to film what to visible world is to paiting or the acoustic world to music. As the objectifying recreation of this type of experiencia, 
film become art. The technological medium par excellence is thus intimately related to the beauty of nature (p. 199).

Una expresión de distancia con respecto al primer momento de la formulación del concepto de IC, y que versa sobre una de sus tesis centrales, la consignó Adorno en su ensayo Tiempo libre (1969). En este, a partir de un trabajo de investigación empírica, Adorno constata que la manipulación y la ingenuidad que en un principio atribuyó a los consumidores de los productos de la IC no coinciden, al menos totalmente, con la experiencia. Aunque con cautela, Adorno reconoce que participar del entretenimiento que ofrecen los mass media no implica necesariamente perder el carácter crítico:

[...] como la industria cultural se ha vuelto total, un fenómeno de lo que siempre es igual, aunque nos promete distraernos temporalmente de esto, hay que dudar que la equiparación de industria cultural y consciencia de los consumidores sea correcta. Hace unos años llevamos a cabo en el Instituto de Investigación Social de Fráncfort un estudio sobre este problema. [... Este estudio se basaba en el estudio de la boda de la princesa Beatriz de Holanda con el diplomático alemán Claus von Amsberg. [...] creíamos que se activaría la ideología de la personalidad, que caracteriza a nuestro tiempo y consiste en que, para compensar la funcionalización de la realidad, se exagera la importancia de las personas y las relaciones privadas frente a lo determinante en la sociedad. Con toda cautela afirmo que nuestras expectativas eran demasiado simples (2009b, p. 581).

Pese a todo, lo que puede constituir la actualidad del pensamiento de Adorno sobre la IC tiene su origen en los mismos elementos desde donde surgen las críticas que se le pueden formular. La adopción de la perspectiva económica y el carácter expansivo y monopólico que reconoce en el poder económico, dan plena vigencia a su versión de la dialéctica. Bajo el primado de la economía de capital, el mundo social se ha convertido en un gran sistema en el cual solo quedan los intersticios entre sus partes para desvelar la forzada costura que los une. Para estar de acuerdo con Adorno basta pensar, por ejemplo, en cómo grandes grupos económicos son poseedores simultáneamente de industrias relacionadas con la producción de bebidas, cemento, derivados de los hidrocarburos, equipos de fútbol, productoras discográficas y cinematográficas, y medios de comunicación. O en la posesión en los gobiernos, nacionales o regionales, de canales o medios institucionales, incluso trasnacionales como Telesur o Al Yazira, y en el uso que hacen de su participación en los medios privados ${ }^{11}$. O también en cómo un solo grupo, Planeta o Prisa, por mencionar un par de nombres reconocibles en países de lengua castellana, son propietarios únicos o mayoritarios de canales e informativos de televisión, cadenas radiales, medios escritos y editoriales, todos y cada uno con sus respectivos portales en Internet, cuentas en Facebook y Twitter. En su época, Adorno valoró como los sectores poderosos de la industria a los del acero, el petróleo, la electricidad y la química. Y añadió: "Los monopolios culturales son, comparados con ellos, débiles y dependientes" (1998, p, 167). Sin duda, a este respecto la visión de Adorno se quedó corta a la luz de hoy.

11 Un inventario amplio y reciente de cómo está organizado y distribuido el poder mediático en el mundo, incluidos Occidente, Asia y los mundos árabe y musulmán, es el libro de Frédéric Martel Cultura mainstream. 
Con sus críticas y polémicas reflexiones Adorno es uno de los fundadores del análisis de la cultura contemporánea. Desde la parcialidad de su postura, fija términos y perspectivas que luego han sido desarrollados o que han derivado en nuevos planteamientos de autores posteriores. En las consideraciones de Adorno sobre la IC se encuentran elementos pertinentes para pensar la cultura global y mediática contemporánea, pero se hace necesario ponerlos en relación con conceptos formulados posteriormente, desde otras perspectivas y desde otras disciplinas, para no incurrir en lecturas mecanicistas que desconocen la complejidad de las configuraciones culturales, del modo como se hace la producción y la apropiación de los bienes culturales incluso en el ámbito restringido del arte. Por último, merece la pena agregar que en la postura de Adorno se puede leer una amarga exageración. Señalar esto como una crítica, por lo demás, no es agregar mucho. Pues el propio Adorno, a propósito de la pregunta por la comprensión del pasado, que en su caso era un diagnóstico histórico, sostuvo lo siguiente: "He exagerado lo sombrío, siguiendo la máxima de que hoy la exageración es el único medio de la verdad" (2009c, p. 499). Sería más oportuno añadir que al exagerar Adorno tenía razón en lo que anima su crítica al poder: la hipérbole se impone ante lo hiperbólico que ha llegado a ser el dominio ganado por la ideología del dinero, que hoy parece ser la única ideología del poder.

\section{Referencias bibliográficas de Theodor Adorno}

Adorno Theodor. "Transparencies on film". New German Critique, N 24/25, Special Double Issue on New German Cinema (Autumm, 1981 - Winter, 1982), p. 199-205. Tomado de http://es.scribd.com/ doc/37477366/Theodor-Adorno-Transparencies-on-Film. Consulta en abril de 2011

(2003). "¿Es jovial el arte?". En Notas sobre literatura. Madrid: Akal, p. 579-586. (2004). Teoría estética. Madrid: Akal.

Akal, p. 295-302.

(2008). "Resumen sobre la industria cultural". En Crítica de la cultura y sociedad I. Madrid:

(2009a). "Sobre el carácter fetichista de la música y la regresión de la escucha". En

Disonancias. Madrid: Akal, pp. 15-50.

(2009b). "Tiempo libre". En Crítica de la cultura y sociedad II. Madrid: Akal, p. 573-582.

(2009c). "¿Qué significa elaborar el pasado?”. En Crítica de la cultura y sociedad II. Madrid:

Akal, p. 489-503.

Horkheimer Max, Adorno Theodor (1998). Dialéctica de la Ilustración. Madrid: Trotta.

\section{Referencias bibliográficas sobre Theodor Adorno}

Bustamante Enrique (ed.) (2011). Industrias creativas. Amenazas sobre la cultura digital. Barcelona: Gedisa. Carroll Nöel (2002). Una filosofía del arte de masas. Madrid: Machado libros.

Dipaola E., Yabkowski N. (2008). En tu ardor y en tu frío. Arte y política en Theodor Adorno y Gilles Deleuze. Buenos Aires: Paidós.

Jimenez Marc (2001). Theodor Adorno. Arte, ideología y teoría del arte. Buenos Aires: Amorrortu. 
Kellner Douglas (2002). "Adorno and the Dialectics of mass culture". En Gibson N., Rubin A. (eds.). Adorno. A critical reader. Masachusetts: Blackwell, pp. 86-109.

Leyva Gustavo (ed.) (2005). La teoría crítica y las tareas actuales de la crítica. Barcelona: Anthropos.

Martel Frédéric (2011). Cultura mainstream. Cómo nacen los fenómenos de masas. Taurus: México.

Martín-Barbero Jesús (2003). De los medios a las mediaciones. Bogotá: CAB.

Mato Daniel (julio-diciembre 2007). "Todas las industrias son culturales: crítica de la idea de «industrias culturales» y nuevas posibilidades de investigación". Comunicación y Sociedad, N 8, pp. 131 154.

VAA (1982). Industrias culturales: El futuro de la cultura en juego. México: FCE-Unesco. 
